\title{
I-R system of hybrid dysgenesis in Drosophila melanogaster: analysis of the mitochondrial DNA in reactive strains exhibiting different potentials for I factor transposition
}

\author{
YANNICK AZOU* \& JEAN-CLAUDE BREGLIANO \\ Laboratoire de Génétique et Physiologie du Développement, IBDM, CNRS/INSERM, Université de la Méditerranée, \\ AP de Marseille, Parc Scientifique de Luminy, Case 907, 13288, Marseille Cedex 9, France
}

\begin{abstract}
In the I-R hybrid dysgenesis system, Drosophila melanogaster strains fall into two categories denoted inducer (I) and reactive (R). Among the reactive strains we can distinguish strains with weak, medium or strong reactivity levels. These levels are inherited in a complex way involving both chromosomal and nonchromosomal determinants, the nonchromosomal determinant being mainly maternally inherited. We were interested in determining the molecular basis of this maternal transmission. In this article we analyse the possible implication of the mitochondrial DNA in the determination of the reactivity levels. The mtDNA was analysed in lines with very different reactivity levels with the aim of correlating sequence differences with reactivity levels. The mtDNA was analysed by sequencing and restriction fragment length. No correlation was established between reactivity level and mtDNA sequence. This may favour the hypothesis that epigenetic changes would be responsible for the different reactivity levels and their transgenerational transmission.
\end{abstract}

Keywords: Drosophila melanogaster, maternal component, mtDNA sequence, reactive strains.

\section{Introduction}

I-R hybrid dysgenesis was described in the early 1970s (Picard \& L'Héritier, 1971). In this system Drosophila melanogaster strains fall into two categories denoted inducer (I) and reactive (R). Inducer flies carry active copies of the $I$ factor (a LINE-like retrotransposon) on their chromosome, whereas reactive flies do not bear any active $I$ factor in their genome. The dysgenic traits are observed in $F_{1}$ females resulting from a dysgenic cross between reactive females and inducer males. In the oogenesis of these $F_{1}$ females (called SF females for 'Sterile Females'), the transposition of active $I$ elements may occur at a high rate, leading to high levels of mutations, chromosomal rearrangements and nondisjunctions. These genetic abnormalities are associated with nonhatching of some eggs. The percentage of these nonhatching eggs in such a dysgenic cross may vary

*Correspondence. E-mail: azou@lgpd.uni-mrs.fr

Accession number of the sequence in the EMBL Nucleotide Sequence Database: AJ400907. within a wide range, depending on the reactive parental stock used in the cross (Bucheton et al., 1976). According to the percentage of the nonhatching eggs, one can distinguish reactive strains with a weak, medium or strong reactivity level. All available data indicate that in a dysgenic cross, the reactivity level of the $\mathrm{R}$ mothers regulates the transposition rate of the $I$ factor.

Significant characteristics of the reactivity levels are the following: (i) reactivity levels are determined by a cellular state present in the mature oocytes of the reactive females (Bucheton \& Bregliano, 1982) which is inherited mainly maternally from one generation to the next, the chromosomes appearing as the major determinants only after several generations (Bucheton \& Picard, 1978); (ii) nongenetic factors such as females ageing, inhibitors of nucleotide synthesis and gamma rays can modify the reactivity levels and these modifications are maternally heritable, cumulative over generations and always reversible when the treatment is stopped (Bucheton, 1979; Bregliano et al., 1995; Laurençon \& Bregliano, 1995); (iii) reactivity levels correlate with recombination and DNA repair during female meiosis, suggesting that 
reactivity may correspond to a more general biological function beyond the sole regulation of the $I$ factor transposition (Laurençon et al., 1997).

As mentioned above the reactivity levels are inherited in a complex way involving both chromosomal and nonchromosomal determinants, the nonchromosomal determinant being mainly maternally inherited. This was shown by using balanced chromosomes in order to replace, over three generations of crosses, the nuclear genome of a strong reactive strain by that of a weak one. Such lines were strongly reactive at first and underwent a progressive evolution toward a weak reactivity level. This evolution could take as long as 10 generations (Bucheton \& Picard, 1978). A reciprocal scheme gave the same kind of results (i.e. a progressive evolution to strong reactivity level; J.C. Bregliano, unpublished results). We were interested in determining the molecular basis of the maternally inherited component of the reactivity levels. Mitochondria and symbiotes are good examples of cytoplasmic components which could interfere with the chromosomal determinants and modify the cell functioning. In the past, several assays aimed at relating the reactivity levels to the presence of symbiotes have failed (for review see Bregliano \& Kidwell, 1983). The mitochondrial DNA (mtDNA) had also been analysed to test its possible involvement in the $\mathrm{I}-\mathrm{R}$ system of dysgenesis. The study was performed by comparison between inducer and reactive strains; no difference was found between these two types of strain (Picard \& Wolstenholme, 1980).

In the light of the recent data suggesting that differences in reactivity levels are correlated with differences in a basic biological process such as repair and meiotic recombination (Bregliano et al., 1995), it appeared that looking for differences between inducer and reactive strains was not the appropriate way to address the question of the molecular basis of this maternal component. It appeared more relevant to analyse the mtDNA in isogenic strains with different levels of reactivity. In Drosophila some cases of heteroplasmy are known for which the relative proportion of the different mtDNA variant can change. A Drosophila subobscura strain possesses two types of mtDNA, the normal one and a variant deleted in the coding region. These two types of mtDNA are regularly transmitted over generations and their relative amounts appear to be tissue specific and vary during the course of development (Béziat et al., 1993; Lecher et al., 1994). In D. mauritiana as well as in D. melanogaster one case of heteroplasmy is known where two mtDNA length variants that differ in the $\mathrm{A}+\mathrm{T}$-rich region coexist. In both cases the proportion of the long mtDNA variant increases in offspring as the females age (Solignac et al., 1987; Kann et al., 1998).
As mentioned above ageing is one of the nongenetic factors which can modify the reactivity level of the females. The reactivity level of strong or medium reactive females decreases as the females get older. This age-dependent variation is maternally transmitted over several generations (Bucheton, 1979).

This similarity in the age-dependent evolution of the reactivity levels in our strains and of the proportion of different mtDNA variants in others induced us to work on the following assumption: if two mtDNA variants are present in the reactive strains, their relative amounts might be under the control of the chromosomal determinants but could also be modulated by nongenetic factors. If each of these variants is involved in some way in the determinism of the reactivity levels, these levels would depend on the relative amounts of each variant. On that hypothesis, we must assume that a line with a low level of reactivity will be enriched in one type of mtDNA variant while an isogenic line, with a high level of reactivity, will be enriched in the other variant; the comparison of the mtDNA between these two lines would be expressed as differences between these sequences.

In this paper we describe our results from research on a length or a sequence difference between mtDNA of D. melanogaster lines with the same genetic background and with very strong and weak reactivity levels.

\section{Materials and methods}

\section{Drosophila stocks and culture conditions}

The est $M$ stock is a strongly reactive stock bearing the ebony mutation. With this stock we used the agedependent variation of the reactivity level to obtain isogenic lines with very different levels of reactivity (Bucheton, 1979). Sublines bred with a short generation pattern, i.e. each generation being recovered from young mothers (1-3 days old), retain a strong reactivity level. In sublines bred with a long generation pattern, i.e. each generation being recovered from old mothers (30-45 days old), the reactivity level progressively decreases to reach a low value, which remains stable as long as the long generation pattern is maintained. These sublines are denoted SG (for Short Generation) and LGx (for Long Generation with $\mathrm{x}$ indicating the number of long generations). Paris is a reactive stock obtained in Paris in 1952. This stock was very weakly reactive for many years and then became polymorphic for reactivity levels. $P 1 m$ and $P F 9 b$ are lines, respectively, weak and strong, isolated from this stock nearly 15 years ago and maintained with short generation pattern. Culture conditions were as described in Bregliano et al. (1995). 


\section{Measure of the reactivity level}

The reactivity levels were measured by the percentage of nonhatching eggs after a dysgenic cross between reactive females and inducer males (B2' or Canton S strains) as previously described (Bregliano et al., 1995).

\section{DNA analysis}

Fifteen $\mu \mathrm{g}$ of total DNA was analysed by Southern blot (Southern, 1975) after digestion by HindIII, EcoRI or MboI. Probes were Drosophila melanogaster mtDNA fragments prepared from mtDNA sequences cloned in pGEM7 Zf or pGEM3 Zf (a gift from S. Alziari) and describe in Béziat et al. (1993). Probes were ${ }^{32} \mathrm{P}$-labelled by random priming (Amersham Megaprime kit).

\section{DNA amplification and sequencing}

The sequenced templates were obtained by PCR amplification of five overlapping fragments covering the mtDNA from position 37 to position 14462 (positions refer to the numeration of the published sequence ID.MIDMMU375; (Lewis et al., 1995)). Five pairs of primers were used, and their sequences are given below.

1-R: GTAAATCATGCAGTTTTCTG (37),

1-L: GATCCATTATGACCTGATGG (4267);

2-R: TCAGAAATCTGTGGGGCTAATC (3671),

2-L: TTGTTTATATGTGCTGGGGC (7209);

3-R: GAAGCAGCTGCATGATATTGAC (5444),

3-L: GTATGTGAAGGGGCCTTAGG (9633);

4-R: CAGCTTGTAAACGTTCTGGC (9127),

4-L: AGATTGCGACCTCGATGTTG (12 943);

5-R: AGGACGAGGAATTTATTACGG (10 794);

5-L: ATTAATCCACGATGGACCTTAC (14 463).

The numbers refer to the positions of the $5^{\prime}$ end of each primer on the previously published sequence (MIDMMU375) and letters to the direction of elongation with respect to that sequence. Fragments were amplified with a mix of Taq DNA and Pwo DNA polymerases (Expand ${ }^{\mathrm{TM}}$ High Fidelity PCR System, Boehringer Mannheim) according to the manufacturer's instructions. Sequences were subcontracted to the private company, Genome Express (SA).

\section{Results}

\section{Comparison of restriction fragment lengths}

The fragment length polymorphism was analysed on HindIII, Eco RI or MboI digestions of mtDNA from two couples of isogenic lines to study regions previously mentioned as polymorphic, for example the HindIII fragment encompassing the A + T-rich region or some MboI fragments (Solignac et al., 1983; Hale \& Singh, 1991). The pair of isogenic lines used were the est $M$ LG49-est $M$ SG (reactivity levels, respectively, $10 \%$ and $100 \%$ ) for which the difference in the reactivity levels is a consequence of ageing of the females and $P 1 m-P F 9 b$ (reactivity levels, respectively, $8 \%$ and $100 \%$ ) for which the difference in the reactivity level is constitutive (see Materials and methods). The overall length of the mtDNA is about $18.3 \mathrm{~kb}$ for the Paris strain and $18.8 \mathrm{~kb}$ for the est $M$ one. This is due to the length of the HindIII fragment encompassing the $\mathrm{A}+\mathrm{T}$-rich region which measures $4.6 \mathrm{~kb}$ and $5.1 \mathrm{~kb}$ for the Paris strain and est $M$ strain, respectively.

No difference in the length of the different restriction fragments was detected in relation to the reactivity level. With this technique, deletion or insertion less than 100 bp could not be detected.

\section{Comparison of the sequence of the coding region}

It has been shown, in some kinds of heteroplasmy, that the relative proportions of the different variants could be age-dependent (Solignac et al., 1987; Kann et al., 1998), so we preferred, in a first approach, to compare the nucleotide sequence in lines which have constitutive different levels of reactivity, i.e. PIm and PF9b, to avoid differences due to a possible age-dependent effect.

A sequence of 14365 nucleotides, which corresponds to $96.4 \%$ of the coding sequence, has been determined, on both strands, for the two strains PIm (reactivity level $8 \%$ ) and PF9b (reactivity level $100 \%$ ). It starts at position 46 of the sequence previously published in the data bank (ID. MIDMMU375) and ends at position 14 417. Each base has been sequenced at least twice (usually three or four times) and we found no difference between the two mtDNA sequences coming from these two lines. In these technical conditions, we would have detected the presence of two DNA variants with at least one nucleotide change and whose proportions differ by at least $30 \%$ between the two strains. Below this value it becomes possible that the background noise hides the presence of the variants.

\section{Analysis of the sequence of the Paris lines}

The sequence we found for the Paris lines (ID. AJ400907) differs from that already published (ID. MIDMMU375) by 69 differences. Among them is the 6 bp-insertion (positions 7131-7136 in MIDMMU375) already mentioned by Rand et al. (1994) which could correspond to a cloning artefact in the sequence of Garesse (Garesse, 1988). Two differences correspond 
Table 1 Sequence comparison between the previously published sequence (MIDMMU375) and that of the Paris strain (AJ400907) of Drosophila melanogaster

\begin{tabular}{|c|c|c|c|c|c|}
\hline Genes & $\begin{array}{c}\text { Bases } \\
\text { (MIDMMU375) }\end{array}$ & $\begin{array}{l}\text { Bases } \\
\text { (Paris) }\end{array}$ & $\begin{array}{l}\text { Position } \\
\text { (Paris) }\end{array}$ & $\begin{array}{l}\text { Amino- } \\
\text { acid }\end{array}$ & $\begin{array}{l}\text { Position } \\
\text { in codon }\end{array}$ \\
\hline \multirow[t]{7}{*}{$N D 2$} & $\mathrm{C}$ & $\mathrm{T}$ & 630 & $\mathrm{~L}$ & 3 \\
\hline & G & A & 769 & $\mathrm{~S}$ & 3 \\
\hline & $\mathrm{C}$ & $\mathrm{T}$ & 694 & $\mathrm{~L}$ & 1 \\
\hline & A & G & 750 & G & 3 \\
\hline & $\mathrm{T}$ & A & 797 & $\mathrm{Y}(\mathrm{L})$ & \\
\hline & A & $\mathrm{T}$ & 798 & $\mathrm{Y}(\mathrm{L})$ & \\
\hline & A & $\mathrm{C}$ & 1027 & $\mathrm{~L}(\mathrm{I})$ & 1 \\
\hline \multirow{10}{*}{$C O I$} & G & A & 1633 & M & 3 \\
\hline & A & $\mathrm{T}$ & 1738 & $\mathrm{~L}$ & 3 \\
\hline & A & G & 1795 & G & 3 \\
\hline & A & G & 1816 & $\mathrm{P}$ & 3 \\
\hline & $\mathrm{T}$ & $\mathrm{C}$ & 1820 & $\mathrm{~L}$ & 1 \\
\hline & G & A & 1888 & G & 3 \\
\hline & $\mathrm{T}$ & $\mathrm{C}$ & 2119 & Y & 3 \\
\hline & $\mathrm{C}$ & $\mathrm{T}$ & 2146 & $\mathrm{H}$ & 3 \\
\hline & $\mathrm{C}$ & $\mathrm{T}$ & 2620 & $\mathrm{P}$ & 3 \\
\hline & $\mathrm{C}$ & $\mathrm{T}$ & 2821 & I & 3 \\
\hline \multirow{3}{*}{ CO II } & G & A & 2923 & $\mathrm{P}$ & 3 \\
\hline & $\mathrm{T}$ & $\mathrm{C}$ & 3476 & $\mathrm{P}$ & 3 \\
\hline & $\mathrm{T}$ & $\mathrm{C}$ & 3542 & A & 3 \\
\hline \multirow[t]{5}{*}{ ATPase 6} & $\mathrm{~T}$ & $\mathrm{C}$ & 4055 & $\mathrm{~S}(\mathrm{~L})$ & 2 \\
\hline & A & $\mathrm{C}$ & 4206 & $\mathrm{G}$ & 3 \\
\hline & A & G & 4386 & $\mathrm{~T}$ & 3 \\
\hline & $\mathrm{T}$ & C & 4558 & $\mathrm{P}(\mathrm{S})$ & 1 \\
\hline & A & G & 4579 & $\mathrm{~V}(\mathrm{M})$ & 1 \\
\hline \multirow{3}{*}{ CO III } & $\mathrm{C}$ & $\mathrm{T}$ & 4721 & $\mathrm{~F}$ & 3 \\
\hline & A & G & 5171 & Q & 3 \\
\hline & $\mathrm{C}$ & $\mathrm{T}$ & 5306 & $\mathrm{~F}$ & 3 \\
\hline$N D 3$ & A & G & 5902 & M & 3 \\
\hline Noncoding & A & $\mathrm{T}$ & 5926 & & \\
\hline Noncoding & $\mathrm{T}$ & A & 5928 & & \\
\hline$t R N A G l u$ & $\mathrm{C}$ & $\mathrm{T}$ & 6264 & & \\
\hline \multirow[t]{4}{*}{ ND5 } & $\mathrm{C}$ & $\mathrm{T}$ & 6959 & $\mathrm{I}(\mathrm{M})$ & 3 \\
\hline & G & A & 7133 & $\mathrm{H}$ & 3 \\
\hline & G & A & 7823 & $\mathrm{~F}$ & 3 \\
\hline & G & A & 7841 & $\mathrm{~F}$ & 3 \\
\hline \multirow[t]{5}{*}{$N D 4$} & A & G & 8897 & $\mathrm{H}(\mathrm{Y})$ & 1 \\
\hline & $\mathrm{C}$ & A & 8898 & V & 3 \\
\hline & A & G & 8958 & Y & 3 \\
\hline & $\mathrm{T}$ & A & 8997 & $\mathrm{~S}$ & 3 \\
\hline & A & G & 9140 & $\mathrm{~L}$ & 1 \\
\hline$N D 4 L$ & G & A & 9736 & $\mathrm{~L}$ & 1 \\
\hline \multirow[t]{3}{*}{ ND6 } & $\mathrm{C}$ & $\mathrm{T}$ & 9943 & Y & 3 \\
\hline & $\mathrm{C}$ & $\mathrm{T}$ & 10178 & $\mathrm{~L}$ & 1 \\
\hline & $\mathrm{C}$ & $\mathrm{T}$ & 10342 & $\mathrm{P}$ & 3 \\
\hline \multirow[t]{3}{*}{$c y t b$} & $\mathrm{~T}$ & G & 10878 & $\mathrm{G}(\mathrm{V})$ & 2 \\
\hline & $\mathrm{T}$ & A & 10888 & V & 3 \\
\hline & A & C & 10905 & $\mathrm{~S}(\mathrm{~T})$ & \\
\hline
\end{tabular}

(c) The Genetics Society of Great Britain, Heredity, 86, 110-116. 


\begin{tabular}{lccccc}
\hline Genes & $\begin{array}{c}\text { Bases } \\
\text { (MIDMMU375) }\end{array}$ & $\begin{array}{c}\text { Bases } \\
(\text { Paris })\end{array}$ & $\begin{array}{c}\text { Position } \\
\text { (Paris) }\end{array}$ & $\begin{array}{c}\text { Amino- } \\
\text { acid }\end{array}$ & $\begin{array}{c}\text { Position } \\
\text { in codon }\end{array}$ \\
\hline \multirow{6}{*}{ ND1 } & $\mathrm{C}$ & $\mathrm{A}$ & 10906 & $\mathrm{~S}(\mathrm{~T})$ & \\
& $\mathrm{C}$ & $\mathrm{T}$ & 11218 & $\mathrm{~N}$ & \\
& $\mathrm{C}$ & $\mathrm{A}$ & 11232 & $\mathrm{~N}(\mathrm{~T})$ & 2 \\
& $\mathrm{~T}$ & $\mathrm{C}$ & 11513 & $\mathrm{~L}$ & 1 \\
& $\mathrm{~T}$ & $\mathrm{~A}$ & 11846 & $\mathrm{~F}(\mathrm{I})$ & 1 \\
& $\mathrm{G}$ & $\mathrm{C}$ & 11869 & $\mathrm{G}(\mathrm{P})$ & \\
Large rRNA & $\mathrm{G}$ & $\mathrm{C}$ & 11870 & $\mathrm{G}(\mathrm{P})$ & 3 \\
& $\mathrm{C}$ & $\mathrm{A}$ & 11940 & $\mathrm{~F}(\mathrm{~L})$ & 3 \\
& $\mathrm{~T}$ & $\mathrm{G}$ & 12013 & $\mathrm{~T}(\mathrm{~N})$ & 2 \\
& $\mathrm{C}$ & $\mathrm{T}$ & 12044 & $\mathrm{M}(\mathrm{V})$ & 1 \\
& $\mathrm{~T}$ & $\mathrm{C}$ & 12579 & $\mathrm{~L}$ & 3 \\
\hline
\end{tabular}

Bases (MIDMMU375) refer to the bases in that sequence.

Bases (Paris) refer to the bases in that strain.

Position (Paris) refers to the number of the base in the Paris sequence.

Amino-acid refers to the one encoded by the Paris sequence. The amino-acid encoded by the MIDMMU375 sequence is indicated in parentheses.

Position in codon refers to the position of the modified base in the codon.

The entries in italics in column 3 refer to nucleotides in which there are possible errors either in the Paris sequence or in the previously published sequence, so they were not taken in account as amino-acid substitutions.

to a one-base deletion in the Paris strain (position 13214 and 13288 in MIDMMU375). The 61 remaining differences probably reflect strain-dependent variations such as have been observed in other D. melanogaster mtDNA sequence comparisons (de Bruijn, 1983; Kaneko et al., 1993; Ballard \& Kreitman, 1994; Rand et al., 1994; Lewis et al., 1995). These differences are summarized in Table 1. Genes for rRNA or tRNA are modified three times and two differences are in a noncoding region. Of the 56 remaining differences 44 are synonymous and 12 are
Table 1 (Continued) nonsynonymous. If we consider the overall pattern of the amino-acid substitutions, some regions appeared to be more subject to substitutions than others, i.e. the region of the ATPase 6 subunit gene and of the ND1 subunit gene. Kaneko et al. (1993) have studied the polymorphism in the ATPase 6 subunit gene; we found the amino-acid substitutions mentioned by these authors (positions 4055, 4558, 4579, see Table 1). This suggests that these amino-acid polymorphisms are widespread in D. melanogaster. In this region we found two other polymorphisms which are silent mutations

Table 2 Polymorphic sites in the ATPase 6 subunit gene

\begin{tabular}{lllllll}
\hline & \multicolumn{5}{c}{ Nucleotide position } \\
\cline { 2 - 6 } Strains & 4055 & \multicolumn{1}{c}{4206} & 4386 & 4553 & 4558 & 4579 \\
\hline mel-1 & L (TTA) & G (GGA) & T (ACA) & N (AAT) & S (TCT) & M (ATA) \\
mel-2 & S (TCA) & G (GGT) & T (ACA) & N (AAT) & P (CCT) & V (GTA) \\
$S P-1$ & S (TCA) & G (GGT) & T (ACA) & K (AAA) & S (TCT) & M (ATA) \\
$I R-17$ & S (TCA) & G (GGT) & T (ACA) & N (AAT) & P (CCT) & V (GTA) \\
Paris & S (TCA) & G (GGC) & T (ACG) & N (AAT) & P (CCT) & V (GTA) \\
Position & 4055 & 4206 & 4386 & 4553 & 4558 & 4579 \\
Codon number & 12 & 62 & 122 & 177 & 180 & 187 \\
\hline
\end{tabular}

mel- 1 and $m e l-2$ correspond to the sequences published by de Bruijn (1983); $S P-1$ and $I R-17$ correspond to sequences published by Kaneko et al. (1993).

Position: refers to the nucleotide position in the sequence of the Paris strains.

Codon number: refers to that of the previously published sequence MIDMMU375. 
(positions 4206 and 4386). Position 4206 (a glycine residue) appeared to be highly polymorphic, as three different glycine codons were found in the different strains analysed so far (see Table 2 and Kaneko et al., 1993).

\section{Discussion}

We have compared the mtDNA between lines of Drosophila melanogaster which exhibit strong and low reactivity levels, with the aim of looking for differences in the sequence which could be correlated with these reactivity levels. The aim of this study is based on the assumption that differences in the mitochondrial sequence between these two strains could involve the presence of two variants (heteroplasmy) in each strain, the relative amounts of which might be correlated with the reactivity level.

In Drosophila melanogaster the mtDNA is about $18 \mathrm{~kb}$ to $19 \mathrm{~kb}$ long and composed of an A + T-rich region (4 $\mathrm{kb}$ to $5 \mathrm{~kb}$ long) which contains the replication origin and a coding region encoding for 13 polypeptides all implicated in oxidative phosphorylation, coding for 22 tRNA and two rRNA. We analyse the mtDNA by restriction fragment length and DNA sequencing. The analysis of the restriction fragment length allowed us to compare the HindIII fragment encompassing the $\mathrm{A}+\mathrm{T}$-rich region and the sequencing approach allowed us to compare more precisely the coding region. About $96 \%$ of the coding region was sequenced in two lines of the Paris stock.

Within the limits of these techniques we can assume that no heteroplasmy is linked to the modulation of the reactivity levels. This result strengthens the hypothesis that this modulation is due to epigenetic changes.

Within the past years our group has shown that the reactivity levels are closely linked to a DNA repairrecombination system which has been called VAMOS for VAriability MOdulation System. As for the reactivity levels, the changes induced on the VAMOS are transmitted by females only and may be slowly accumulated over generations (Laurençon \& Bregliano, 1995). Polycomb group and trithorax group gene products are responsible for the maintenance of repressed and active expression patterns of many regulatory genes. Recent data show that epigenetically determined active or repressed states can be transmitted to the next generation through the female germ-line, suggesting that a protein-based cellular memory mechanism can be propagated through meiosis (Cavalli \& Paro, 1998). Recently Jensen et al. (1999) have shown that the transposition of incoming $I$ factor could be silenced by the prior transgenesis of a fragment of this factor. This repression of the $I$ factor activity develops in a generation-dependent manner, via female germ-line

(c) The Genetics Society of Great Britain, Heredity, 86, 110-116. transmission. This autoregulation presents the characteristic features of homology-dependent gene silencing or cosuppression (Jensen et al., 1999). Cosuppression is mediated by a cellular system whose molecular basis is unknown so far. The epigenetic system responsible for transgenerational transmission might imply only nuclear chromatin but we cannot exclude the possibility that it could lie in a complex regulatory process involving biochemical functions of mitochondria.

\section{Acknowledgements}

We especially thank Monique Monnerot for very useful reading of the manuscript. We are grateful to Christophe de La Roche Saint-André for comments on the first draft. This work was supported by the Centre National de la Recherche Scientifique and the Université de la Méditerranée.

\section{References}

BALlARD, J. W. AND KREITMAN, M. 1994. Unravelling selection in the mitochondrial genome of Drosophila. Genetics, 138, 757-772.

BEZIAT, F., MOREL, F., VOLZ-LINGENHOL, A., SAINT-PAUL, N. AND ALZIARI, S. 1993. Mitochondrial genome expression in a mutant strain of D. subobscura, an animal model for large scale mtDNA deletion. Nucl. Acids Res., 21, 387-392.

BREGLIANO, J. C. AND KIDWELl, M. 1983. Hybrid dysgenesis determinants. In: Shapiro, J. A. (ed.) Mobile Genetic Elements, pp. 363-410. Academic Press, New York.

BREgliano, J. C., LAURENÇON, A. AND DEGRoOTE, F. 1995. Evidence for an inducible repair-recombination system in the female germ line of Drosophila melanogaster. I. Induction by inhibitors of nucleotide synthesis and by gamma rays. Genetics, 141, 571-578.

DE BRUIJN, M. H. L. 1983. Drosophila melanogaster mitochondrial DNA, a novel organization and genetic code. Nature, 304, 234-241.

BUCHETON, A. 1979. Non-mendelian female sterility in Drosophila melanogaster: influence of aging and thermic treatments. III. Cumulative effects induced by these factors. Genetics, 93, 131-142.

BUCHETON, A. AND BREgliANO, J. C. 1982. The I-R system of hybrid dysgenesis in Drosophila melanogaster: Heredity of the reactive condition. Biol. Cell, 46, 123-132.

BUCHETON, A. AND PICARD, G. 1978. Non-mendelian female sterility in Drosophila melanogaster: hereditary transmission of reactivity level. Heredity, 40, 207-223.

BUCHETON, A., LAVIGE, J. M., PICARD, G. AND L'HERITIER, P. 1976. Non-mendelian female sterility in Drosophila melanogaster: quantitative variations in the efficiency of inducer and reactive strains. Heredity, 36, 305-314.

CAVAlli, G. AND PARO, R. 1998. The Drosophila Fab-7 chromosomal element conveys epigenetic inheritance during mitosis and meiosis. Cell, 93, 505-518. 
GARESSE, R. 1988. Drosophila melanogaster mitochondrial DNA: gene organization and evolutionary implications. Genetics, 118, 649-663.

HALE, L. R. AND SINGH, R. S. 1991. A comprehensive study of genic variation in natural populations of Drosophila melanogaster. IV. Mitochondrial DNA variation and the role of history vs. selection in the genetic structure of geographic populations. Genetics, 129, 103-117.

JENSEN, S., GASSAMA, M. P. AND HEIDMANN, T. 1999. Cosuppression of $I$ transposon activity in Drosophila by $I$-containing sense and antisense transgenes. Genetics, 153, 1767-1774.

KANEKO, M., SATTA, Y., MATSUURA, E. T. AND CHIGUSA, S. I. 1993. Evolution of the mitochondrial ATPase 6 gene in Drosophila: unusually high level of polymorphism in D. melanogaster. Genet. Res., 61, 195-204.

KANN, L. M., ROSENBluM, E. B. AND RAND, D. M. 1998. Aging, mating, and the evolution of mtDNA heteroplasmy in Drosophila melanogaster. Proc. Natl. Acad. Sci. U.S.A., 95, 2372-2377.

LAURENÇON, A. AND BREGLIANO, J. C. 1995. Evidence for an inducible repair-recombination system in the female germ line of Drosophila melanogaster. II. Differential sensitivity to gamma rays. Genetics, 141, 579-585.

LAURENÇON, A., GAY, F., DUCAU, J. AND BREGLIANO, J. C. 1997. Evidence for an inducible repair-recombination system in the female germ line of Drosophila melanogaster. III. Correlation between reactivity levels, crossover frequency and repair efficiency. Genetics, 146, 1333-1344.
LECHER, P., BEZIAT, F. AND ALZIARI, S. 1994. Tissular distribution of heteroplasmy and ultrastructural studies of mitochondria from a Drosophila subobscura mitochondrial deletion mutant. Biol. Cell, 80, 25-33.

LEWIS, D. L., FARR, C. L. AND KAGUNI, L. S. 1995. Drosophila melanogaster mitochondrial DNA: completion of the nucleotide sequence and evolutionary comparisons. Insect Mol. Biol., 4, 263-278.

PICARD, G. AND L'HERITIER, P. 1971. A maternally inherited factor inducing sterility in Drosophila melanogaster. Drosoph. Inf. Serv., 46, 54.

PICARD, G. AND WOLSTENHOLME, D. R. 1980. SF sterility in Drosophila melanogaster: a comparative study of mitochondrial DNA molecules from flies of inducer and reactive strains. Biologie Cellulaire, 38, 157-162.

RAND, D. M., DORFSMAN, M. AND KANN, L. M. 1994. Neutral and non-neutral evolution of Drosophila mitochondrial DNA. Genetics, 138, 741-756.

SOLIGNAC, M., MONNEROT, M. AND MOUNOLOU, J. C. 1983. Mitochondrial DNA heteroplasmy in Drosophila mauritiana. Proc. Natl. Acad. Sci. U.S.A., 80, 6942-6946.

SOLIGNAC, M., GENERMONT, J., MONNEROT, M. AND MOUNOLOU, J. C. 1987. Drosophila mitochondrial genetics: evolution of heteroplasmy through germ line cell divisions. Genetics, 117, 687-696.

SOUTHERN, E. M. 1975. Detection of specific sequences among DNA fragments separated by gel electrophoresis. J. Mol. Biol., 98, 503-517. 